\title{
Phylogeny of the Kinetoplastida: Taxonomic Problems and Insights into the Evolution of Parasitism
}

\author{
Dmitri A Maslov/ ${ }^{+}$, Sergei A Podlipaev*, Julius Lukeš**
}

\begin{abstract}
Department of Biology, University of California, 3401 Watkins Drive, Riverside, CA 92521, USA
*Zoological Institute, Russian Academy of Sciences, 199034 St. Petersburg, Russia **Institute of Parasitology, Czech Academy of Sciences, 37005 Èeské Budejovice, Czech Republic
\end{abstract}

To further investigate phylogeny of kinetoplastid protozoa, the sequences of small subunit (18S) ribosomal RNA of nine bodonid isolates and ten isolates of insect trypanosomatids have been determined. The root of the kinetoplastid tree was attached to the branch of Bodo designis and/or Cruzella marina. The suborder Trypanosomatina appeared as a monophyletic group, while the suborder Bodonina was paraphyletic. Among bodonid lineages, parasitic organisms were intermingled with free-living ones, implying multiple transitions to parasitism and supporting the 'vertebrate-first hypothesis'. The tree indicated that the genera Cryptobia and Bodo are artificial taxa. Separation of fish cryptobias and Trypanoplasma borreli as different genera was not supported. In trypanosomatids, the genera Leptomonas and Blastocrithidia were polyphyletic, similar to the genera Herpetomonas and Crithidia and in contrast to the monophyletic genera Trypanosoma and Phytomonas. This analysis has shown that the morphological classification of kinetoplastids does not in general reflect their genetic affinities and needs a revision.

Key words: Kinetoplastida - Bodonina - Trypanosomatina - parasitism - phylogeny

Kinetoplastids are a group of protozoa characterized by the presence of a characteristic organelle, the kinetoplast (Vickerman 1976). This structure was observed by early researchers in light microscope as basophilic granules located near the basal body of a flagellum. This association was thought to meaningful, and the term 'kinetoplast' was coined by Alexeieff in 1917 (Alexeieff 1917, Vickerman \& Preston 1976). Only in the 60s, after the first electron microscopic studies of this organelle conducted by Vickerman and Steinert, had it become clear that the kinetoplast represents a portion of a single branched mitochondrion of the cell containing a large mass of mitochondrial DNA. The presence of the kinetoplast is easy to determine by fluorescence with a DNA binding dye DAPI or by Giemsa staining.

This work was supported by the grant 99-04-49-572 from the Russian Foundation of Basic Research to SAP, the grant A6022903 from the Czech Academy of Sciences to JL and also in part by a Burroughs Wellcome New Investigator Award in Molecular Parasitology and the NIH grant AI40634 to DAM.

${ }^{+}$Corresponding author. Fax: 909-787-4286. E-mail: maslov@ucrac1.ucr.edu

Received 13 November 2000

Accepted 3 January 2001
This group of organisms is usually assigned the rank of an order - Kinetoplastida, which, together with two other groups: Euglenida and Diplonemida - belongs to the phylum Euglenozoa (CavalierSmith 1993, Corliss 1994). This assemblage has been confirmed by a number of works, mainly based on the ribosomal SSU RNA phylogenetic analysis, which showed Euglenozoa as a monophyletic group, well separated from the eukaryotic crown (Sogin \& Silberman 1998, Maslov et al. 1999; see Philippe \& Adoute 1998 for a review of protein based phylogenies).

The existing taxonomy of kinetoplastids is based on morphology and life cycles. Traditionally the group is subdivided into two suborders: Bodonina and Trypanosomatina (Vickerman 1976, Lom 1976). The first one includes two families: Bodonidae and Cryptobiidae, members of which have a relatively large kinetoplast and two flagella: anterior (always remains free) and recurrent (free in bodonids and attached in cryptobiids). Bodonids show a variety of life styles, ranging from free living, such as Bodo, Parabodo, Dimastigella, Rhynchobodo, Cruzella, to parasitic. The latter are represented by ectoparasites of the fish skin and gills such as Ichtyobodo, endoparasites of the reproductive tract of snails (some Cryptobia species) and gastro-intestinal tract of fish (some other Cryptobia) and also by digenetic parasites of fish blood (Trypanoplasma) transmitted by leeches. The second group of kinetoplastids, the trypano- 
somatids, forms a single family, Trypanosomatidae, which includes obligatory parasitic organisms with a single flagellum and a small kinetoplast. Trypanosomatids parasitize all classes of vertebrates, as well as some invertebrates, preferentially insects from the orders Diptera and Hemiptera, and also plants. The invertebrates can either represent hosts, as in monogenetic parasites, such as Crithidia, Leptomonas, Herpetomonas and Blastocrithidia, or serve as vectors, as in digenetic genera Trypanosoma, Leishmania and in bug-transmitted parasites of plants, Phytomonas.

The system of the trypanosomatid genus assignment was largely developed by Hoare and Wallace (1966) on the basis of the observed morphotypes (Molyneux \& Ashford 1983). The morphotypes are defined by the relative position of the nucleus and the kinetoplast and the overall body shape. At least two morphotypes are observed in each genus, depending on a life cycle stage and physiological conditions of the cells. Some morphotypes are unique to a certain genus, while others, such as promastigotes, are shared by many genera. This system has been criticized in the past as potentially misleading.

A novel genus, Wallaceina has recently been proposed to include monogenetic insect parasites with an 'endomastigote' morphology, characterized by a long curved flagellar pocket (Podlipaev et al. 1990).

With the progress of molecular biological studies of kinetoplastids it has become increasingly clear that existing taxonomy does not reflect the true genetic affinities in these organisms, calling for the application of molecular phylogenetic methods (McGhee \& Cosgrove 1980, Camargo et al. 1982, Wallace et al. 1983, Kolesnikov et al. 1990, Podlipaev et al. 1991, Dollet 1994, Vickerman 1994, Podlipaev \& Lobanov 1996, Hollar et al. 1998, Wright et al. 1999). The phylogenetic tree can also be used as a framework to study the origin and evolution of parasitism and a number of unique molecular and biochemical mechanisms seen in this group, such as the kinetoplast DNA networks, uridylate-insertional/deletional type of RNA editing, tRNA importation in the mitochondrion, antigenic variation and the others (recently reviewed in Donelson et al. 1999, Simpson et al. 2000).

In the first phylogenetic reconstructions, a relatively small number of available trypanosomatid and only two bodonid SSU sequences were employed (Fernandes et al. 1993, Du et al. 1994, Landweber \& Gilbert 1994, Maslov et al. 1994, 1996, Maslov \& Simpson 1995). The root of the tree was established using Euglena gracilis as the outgroup and was found to be attached in bodonids.
The trypanosomatids formed a so-called paraphyletic tree, according to the topology of trypanosomes. The lineage of Trypanosoma brucei and other trypanosomes were not monophyletic, with $T$. brucei representing the earliest divergence in the family. Other trypanosomes diverged later as a sister-clade to all non-trypanosome genera. The paraphyletic tree was conflicting with the proteinderived trees which all showed trypanosomes as a monophyletic assembly. However, in 1997 it was shown that the paraphyletic topology was a tree reconstruction artefact caused by unequal rate effects (Lukeš et al. 1997). Due to a high rate of sequence divergence in $T$. brucei and the outgroup, the level of accidental similarities (homoplasies) became very high resulting in a placement of these lineages together on a tree. After subdividing the lineages of T. bruce $i$ and outgroups by addition of the new trypanosome and bodonid species, the support for paraphyly of trypanosomes disappeared and support for their monophyly became very strong. This result was later confirmed by other works which utilized a larger number of trypanosome sequences (Haag et al. 1998, Stevens et al. 1999).

The updated trypanosomatid tree published in 1998 was composed of five major clades (Hollar et al. 1998). Only two of them, the clade of Trypanosoma and the clade of Phytomonas, represented examples of consistency between phylogeny and taxonomy. The genera Herpetomonas and Crithidia were polyphyletic: the endosymbiontcontaining members of these genera formed a separate monophyletic clade, while the endosymbiontfree members were found elsewhere on the tree.

The question concerning the status of remaining trypanosomatid genera has been addressed in a more recent work (Merzlyak et al. 2001). The emphasis has been made on isolates from insects identified as Leptomonas, Blastocrithidia and Wallaceina according to their morphology in insect host. In this reconstruction, as in the previous work, the root of the tree was attached between the clade of trypanosomes and the clade of all nontrypanosomes (Fig. 1). Interestingly, among the latter, Blastocrithidia triatoma, was the earliest diverging lineage. Additional analysis has shown that the tree topologically constrained for an earlier divergence of $B$. triatoma is not significantly different from the best unconstrained tree. This indicates that a blastocrithidia-like organism might have been a progenitor of all trypanosomatids, including trypanosomes. This finding is intriguing, because earlier Hoar and Baker hypothesized that such an organism, which they called an "epimastigote" stock, was an ancestral form to most trypanosomes (Baker 1963, Hoare 1972). 
The tree showed that the genus Blastocrithidia is polyphyletic. Two bona fide blastocrithidias, $B$. culicis and $B$. triatoma, were unrelated. The situation with B. gerricola is not clear - this isolate was represented by epimastigotes in the host while only pro- and choanomastigote were observed in culture. It is possible that a mixed infection occurred in the original host. The tree also clearly showed that the genus Leptomonas is polyphyletic as well. This finding was not completely unexpected, taken into account a large extent of genetic variability among the Leptomonas isolates (Camargo et al. 1992) and the lack of truly distinguishing characters for this genus.

With at least four genera of trypanosomatids being polyphyletic (Crithidia, Herpetomonas, Leptomonas and Blastocrithidia), it has become obvious that the morphological taxonomy of trypanosomatids does not reflect their genetic affinities and should be revised in the future. However, there

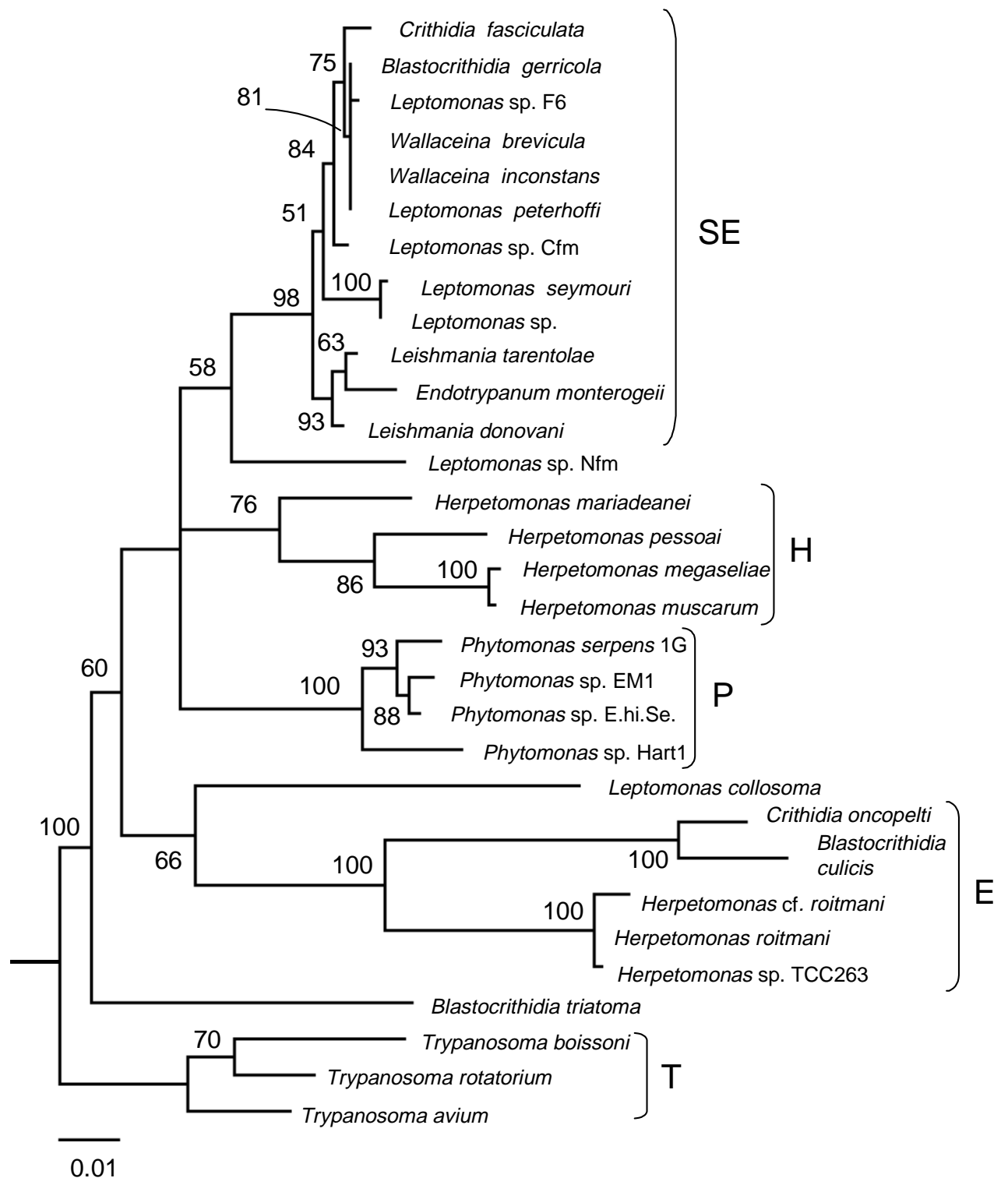

Fig. 1: the maximum likelihood consensus tree of insect trypanosomatids inferred from the small subunit ribosomal RNA sequences (Merzlyak et al. 2001). T- trypanosomes, E - endosymbiont-containing trypanosomatids, P - Phytomonas spp., H endosymbiont-free Herpetomonas spp., SE - trypanosomatids with slowly-evolving SSU rRNA sequences. From Merzlyak et al. (2001) with permission 
is no need to rush. It is clear even from this relatively modest expansion of the number of analyzed isolates that the natural diversity of trypanosomatid is much greater than currently expected. Only after completion of a more satisfactory survey of this group, will it be possible to propose a comprehensive taxonomic system for this group.

The phylogeny of bodonids was investigated in another recent work, which included nine additional bodonid species (Dole $\bullet$ el et al. 2000). The root of the tree (Fig. 2) was determined to be attached to the lineages of free-living organisms Cruzella marina and Bodo designis, thus making bodonids a paraphyletic assembly in contrast to trypanosomatids which separated from bodonids relatively late as a monophyletic group.

As in trypanosomatids, the tree indicated the conflict between taxonomy and phylogeny. It is best exemplified by the polyphyly of the genus Bodo, the members of which are found in the different parts of the tree. Another discrepancy is that the subdivision of the suborder Bodonina onto two families, Bodonidae and Cryptobiidae (Vickerman 1976, 1978), as both members mingle with each other on the tree. A separation of the fish parasites onto the genera Cryptobia and Trypanoplasma, supported by some researchers (Lom 1976, Becker 1977, Brugerolle et al. 1979), and challenged by the others (Bower \& Margolis 1983, Woo 1994), is also not supported.

An interesting feature of the bodonid tree is that free-living species often mingle with parasitic ones. In general, such topology suggests occurrence of the multiple transitions to parasitic life style in the kinetoplastids. Moreover, it seems that this process still continues and different steps of it can be observed in the existing clades. The examples of C. marina and D. trypaniformis, for which both endocommensal and free-living strains have been described, may reflect the very early stages of transition towards endoparasitism. A next step in this direction is illustrated by the endoparasitic $C$. helicis which is likely to have evolved from a freeliving bodonid such as related species B. caudatus, $P$. nitrophilus and B. sorokini. An independent transition to parasitism occurred in the lineage of $T$. borreli - fish Cryptobia spp. In this case, the evolution reached the stage of transition from intesti-
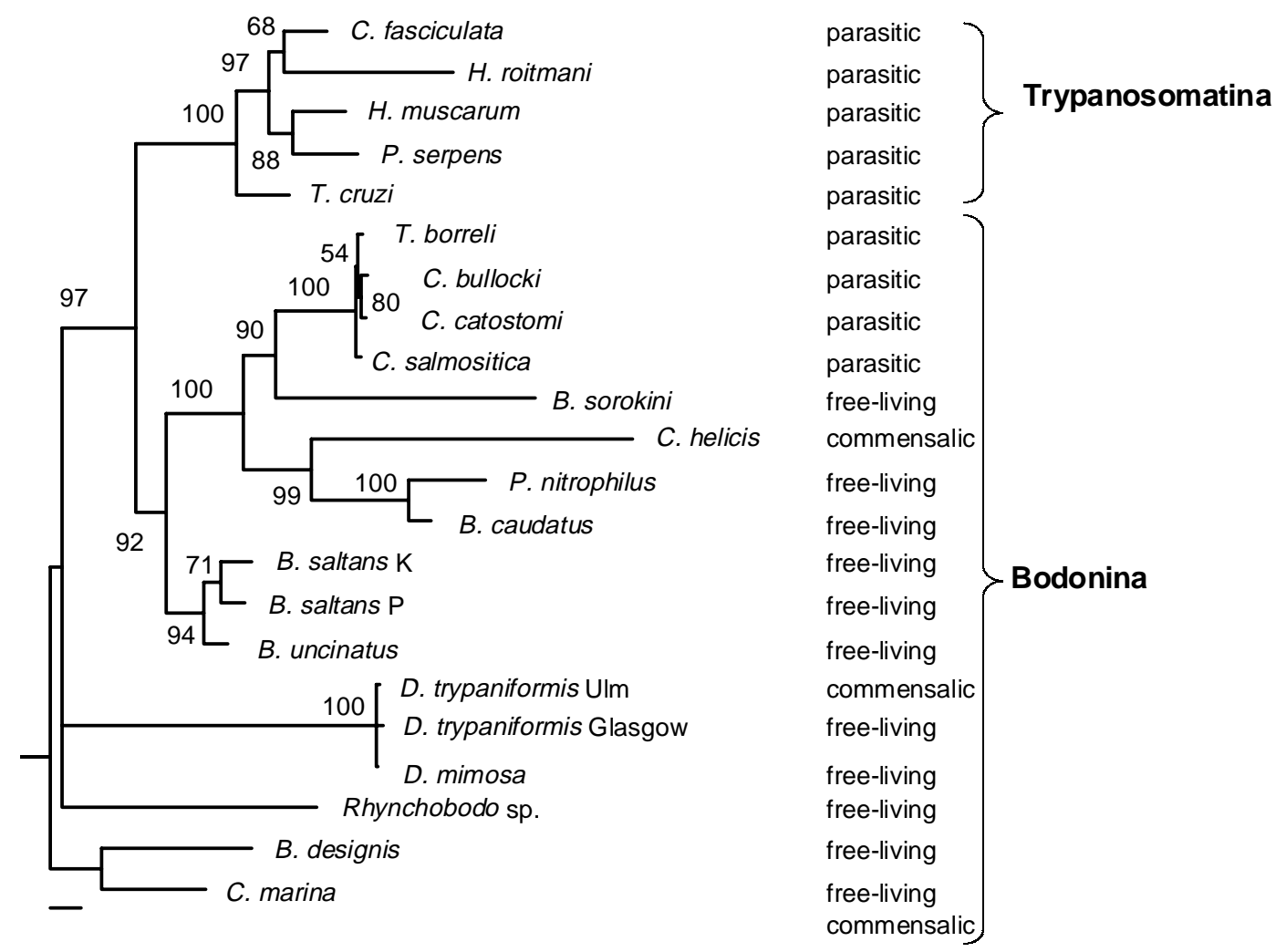

Fig. 2: majority consensus maximum likelihood ribosomal RNA tree of bodonids (Dole $\bullet$ el et al. 2000). Indication of the lifestyle and the hosts is shown on the right. From Dole •el et al. (2000) with permission 
nal parasites to hemoparasites, as this compact group contains both types of organisms. The fact that none of the bodonid groups illustrates the entire evolutionary process should not be surprising. The intermediate stages might have become extinct, in addition the present survey of extant kinetoplastids is incomplete.

Thus the tree topology provides a support to the 'vertebrate first' hypothesis of Minchin (1908) who postulated that the hemoparasites of vertebrates evolved from their endoparasites, which in turn were derived from the free-living species. The results also indicate an independent origin and evolution of parasitism in trypanosomatids. If the evolution in this case had also followed Minchin's scenario, then organisms representing the intermediate stages, such as endoparasitic trypanosomatids of vertebrates, might remain unknown or have become extinct. Alternatively the evolution here might have followed the 'invertebrate first' scenario of Leger (1904) who outlined that original parasites were those infecting the gut of invertebrates (insects) while hemoparasites of vertebrates evolved later.

Finding a monogenetic trypanosomatid, such as B. triatoma, branching off early would support the 'invertebrate first' hypothesis for this case. Therefore, the century-old conflict between the 'vertebrate-first' and 'invertebrate-first' hypotheses might end in a tie, with different routes towards parasitism taken in different evolutionary lineages.

\section{ACKNOWLEDGEMENTS}

To our colleagues who participated in the phylogenetic studies and provided the isolates.

\section{REFERENCES}

Alexeieff A 1917. Mitochondries et corps parabasal chez les flagellés. Comptes Rendus de la Société de Biologie 80: 358-361.

Baker J 1963. Speculations on the evolution of the family Trypanosomatidae Doflein, 1901. Exp Parasitol 13: 219-233.

Becker CD 1977. Flagellate parasites of fish. In JP Kreier, Parasitic Protozoa, Academic Press, New York, v.1, p. 375-416.

Bower SM, Margolis L 1983. Direct transmission of the haemoflagellate Cryptobia salmositica among Pacific salmon (Oncorhynchus spp.). Can J Zool 61: 1242-1250.

Brugerolle G, Lom J, Nohýnková E, Joyon L 1979. Comparaison et évolution des structures cellulaires chez plusieurs especes de Bodonidés et Cryptobiidés appartenant aux genres Bodo, Cryptobia et Trypanoplasma (Kinetoplastida, Mastigophora). Protistologica 15: 197-221.

Camargo EP, Mattei DM, Barbieri CL, Morel CM 1982. Electrophoretic analysis of endonuclease-generated fragments of kDNA, of esterase isoenzymes and surface proteins as aids for species identification of insect trypanosomatids. J Protozool 29: 251-258.

Camargo EP, Sbravate C, Teixeira MMG, Uliana SRB, Soares MBM, Affonso HT, Floeter-Winter L 1992. Ribosomal DNA restriction analysis and synthetic oligonucleotide probing in the identification of genera of lower trypanosomatids. J Parasitol 78: 4048.

Cavalier-Smith T 1993. Kingdom Protozoa and its 18 phyla. Microbiol Rev 57: 953-994.

Corliss JO 1994. An interim utilitarian ("user-friendly") hierarchical classification and characterization of the protists. Acta Protozool 33: 1-51.

Dole• el D, Jirkù M, Maslov DA, Lukeš J 2000. Phylogeny of the bodonid flagellates (Kinetoplastida) based on small subunit rRNA gene sequences. Int $J$ Syst Evol Microbiol 50: 1943-1951.

Dollet M 1994. Identification and characterization of pest organisms: a plant trypanosomes case study. In DL Hawksworth, The Identification and Characterization of Pest Organisms, Cab Int., Wallingford, p. 415-426.

Donelson JE, Gardner MJ, El-Sayed MN 1999. More surprises from Kinetoplastida. Proc Natl Acad Sci USA 96: 2579-2581.

Du Y, Maslov DA, Chang KP 1994. Monophyletic origin of $\beta$-division proteobacterial endosymbionts and their coevolution with insect trypanosomatid protozoa Blastocrithidia culicis and Crithidia spp. Proc Natl Acad Sci USA 91: 8437-8441.

Fernandes AP, Nelson K, Beverley SM 1993. Evolution of nuclear ribosomal RNAs in kinetoplastid protozoa: perspectives on the age and origins of parasitism. Proc Natl Acad Sci USA 90: 11608-11612.

Haag J, O'hUigin C, Overath P 1998. The molecular phylogeny of trypanosomes: evidence for an early divergence of the Salivaria. Mol Biochem Parasitol 91: $37-49$.

Hoare CA 1972. The Trypanosomes of Mammals, Blackwell Scientific, Oxford.

Hoare CA, Wallace FG 1966. Developmental stages of trypanosomatid flagellates: a new terminology. $\mathrm{Na}$ ture 212: 1385-1386.

Hollar L, Lukeš J, Maslov DA 1998. Monophyly of endosymbiont containing trypanosomatids: phylogeny versus taxonomy. J Euk Microbiol 45: 293-297.

Kolesnikov AA, Maslov DA, Podlipaev SA 1990. Comparative restriction enzyme cleavage analysis of kinetoplast DNA from the lower trypanosomatids isolated in the North-West region of the USSR. Arch Protistenk 138: 239-250.

Landweber LF, Gilbert W 1994. Phylogenetic analysis of RNA editing: a primitive genetic phenomenon. Proc Natl Acad Sci USA 91: 918-921.

Léger L 1904. Sur les affinités de l'Herpetomonas subulata et la phylogénie des trypanosomes. $C R$ Sean Soc Biol Ses Fil 56: 615-617.

Lom J 1976. Biology of the trypanosomes and trypanoplasms of fish. In WHR Lumsden, DA Evans (eds), Biology of the Kinetoplastida, Academic Press, London/New York/San Francisco, p. 269-337.

Lukeš J, Jirku M, Dole•el D, Kral'ová I, Hollar L, Maslov DA 1997. Analysis of ribosomal RNA genes 
suggests that trypanosomes are monophyletic. $\mathrm{J} \mathrm{Mol}$ Evol 44: 521-527.

Maslov DA, Simpson L 1995. Evolution of parasitism in kinetoplastid protozoa. Parasitol Today 11: 30-32.

Maslov DA, Yasuhira S, Simpson L 1999. Phylogenetic affinities of Diplonema within the Euglenozoa as inferred from the SSU rRNA gene and partial COI protein sequences. Protist 150: 33-42.

Maslov DA, Avila HA, Lake JA, Simpson L 1994. Evolution of RNA editing in kinetoplastid protozoa. Nature 365: 345-348.

Maslov DA, Lukeš J, Jirkù M, Simpson L 1996. Phylogeny of trypanosomes as inferred from the small and large subunit rRNAs: implications for the evolution of parasitism in the trypanosomatid protozoa. Mol Biochem Parasitol 75: 197-205.

McGhee B, Cosgrove B 1980. Biology and physiology of the lower trypanosomatidae. Microbiol Rev 44: 140-165.

Merzlyak E, Yurchenko V, Kolesnikov AA, Alexandrov K, Podlipaev SA, Maslov DA 2001. Diversity and phylogeny of insect trypanosomatids based on small subunit rRNA genes: polyphyly of Leptomonas and Blastocrithidia. J Euk Microbiol (in press).

Minchin EA 1908. Investigation on the development of trypanosomes in tse-tse flies and other Diptera. $Q J$ Microsc Sci 52: 159-260.

Molyneux D, Ashford R 1983. The Biology of Trypanosoma and Leishmania, Parasites of Man and Domestic Animals. Taylor and Francis, London.

Philippe H, Adoutte A 1998. The molecular phylogeny of Eukaryota: solid facts and uncertainties. In $\mathrm{GH}$ Coombs, K Vickerman, MA Sleigh, A Warren (eds), Evolutionary Relationships among Protozoa, Kluwer Academic Publishers, Dordrecht/Boston/ London, p. 25-56.

Podlipaev SA, Lobanov AL 1996. Use of the measure characters for discrimination of lower trypanosomatids. Parazitologia 30: 324-332 (in Russian).

Podlipaev SA, Frolov AO, Kolesnikov AA 1990. Proteomonas inconstans n. gen., n. sp. (Kinetoplastida: Trypanosomatidae) - a parasite of the bug Calocoris sexguttatus (Hemiptera: Miridae). Parazitologia 24: 339-345 (in Russian).

Podlipaev SA, Malysheva MN, Kolesnikov AA 1991.
Leptomonas rigidus $\mathrm{sp}$. n. (Trypanosomatidae) - a parasite of Salda littoralis L. (Hemiptera: Heteroptera). Acta Protozool 30: 121-127.

Simpson L, Thiemann OH, Savill NJ, Alfonzo JD, Maslov DA 2000. Evolution of RNA editing in trypanosome mitochondria. Proc Natl Acad Sci USA 97: 6986-6993.

Sogin ML, Silberman JD 1998. Evolution of the protists and protistan parasites from the perspective of molecular systematics. Int J Parasitol 28: 11-20.

Stevens JR, Noyes HA, Dover GA, Gibson WC 1999. The ancient and divergent origins of the human pathogenic trypanosomes, Trypanosoma bruce $i$ and T. cruzi. Parasitology 118: 107-116.

Vickerman K 1976. The Diversity of the kinetoplastid flagellates. In WHR Lumsden, DA Evans (eds), Biology of the Kinetoplastida, Academic Press, London/New York/San Francisco, p. 1-34.

Vickerman K 1978. The free-living trypanoplasms: description of three species of the genus Procryptobia n. g., and redescription of Dimastigella trypaniformis Sandon, with notes on their relevance to the microscopic diagnosis of disease in man and animal. Trans Am Micros Soc 97: 485-502.

Vickerman K 1994. The evolutionary expansion of the trypanosomatid flagellates. Int J Parasitol 24: 1317 1331.

Vickerman K, Preston TM 1976. Comparative cell biology of the kinetoplastid flagellates. In WHR Lumsden, DA Evans (eds), Biology of the Kinetoplastida, Academic Press, London/New York/ San Francisco, p. 35-130.

Wallace FG, Camargo EP, McGhee RB, Roitman I 1983. Guidelines for the description of new species of lower trypanosomatids. J Protozool 30: 308-313.

Woo PTK 1994. Flagellate parasites of fishes. In JT Kreier, Parasitic Protozoa, Academic Press, London, p.1-80.

Wright ADG, Li S, Feng S, Martin DS, Lynn DH 1999. Phylogenetic position of the kinetoplastids, Cryptobia bullocki, Cryptobia catostomi, and Cryptobia salmositica and monophyly of the genus Trypanosoma inferred from small subunit ribosomal RNA sequences. Mol Biochem Parasitol 99: 6976. 